\title{
Article \\ Oligomeric Proanthocyanidins and Bamboo Leaf Flavonoids Improve the Quality of Bull Semen Cryopreservation
}

\author{
Hongtao Wang ${ }^{1,2,3,+}$, Ping Lu ${ }^{1,2,3,+}$, Zhiqiang Li 1,2,3, Chongshan Yuan 1,2,3 , Hongyu Liu 1,2,3, Jing Zhao 1,2,3,* \\ Wenfa Lu ${ }^{1,2, *}$ and Jun Wang ${ }^{1,2,3, *}$
}

1 Joint Laboratory of Modern Agricultural Technology International Cooperation, Ministry of Education, Jilin Agricultural University, Changchun 130118, China; hongtao2021@yeah.net (H.W.); luping100419@163.com (P.L.); lizhiqiangsky@126.com (Z.L.); 18844146800@163.com (C.Y.); jlndlhy0133@163.com (H.L.)

2 Key Lab of Animal Production, Product Quality and Security, Ministry of Education, Jilin Agricultural University, Changchun 130118, China

3 College of Animal Science and Technology, Jilin Agricultural University, 2888 Xincheng Street, Changchun 130118, China

* Correspondence: jlndfztd@163.com (J.Z.); wenfa2004@163.com (W.L.); junwang2004@126.com (J.W.); Tel./Fax: +86-0431-84532936 (W.L.)

+ These authors contributed equally to this work.

Citation: Wang, H.; Lu, P.; Li, Z.; Yuan, C.; Liu, H.; Zhao, J.; Lu, W.; Wang, J. Oligomeric

Proanthocyanidins and Bamboo Leaf Flavonoids Improve the Quality of Bull Semen Cryopreservation. Molecules 2022, 27, 1144. https:// doi.org/10.3390/molecules27031144

Academic Editor: Yun-Bae Kim

Received: 10 January 2022

Accepted: 2 February 2022

Published: 8 February 2022

Publisher's Note: MDPI stays neutral with regard to jurisdictional claims in published maps and institutional affiliations.

Copyright: (C) 2022 by the authors. Licensee MDPI, Basel, Switzerland. This article is an open access article distributed under the terms and conditions of the Creative Commons Attribution (CC BY) license (https:/ / creativecommons.org/licenses/by/ $4.0 /)$.

\begin{abstract}
It is important to inhibit oxidative stress to maintain sperm motility during cryopreservation. The present study was performed to investigate the effects of supplementing oligomeric proanthocyanidins (OPC) and bamboo leaf flavonoids (BLF) or their combination as an extender for Simmental bull semen freezing. OPC, BLF, or their combination were added to the frozen diluent of bovine semen. Afterwards, computer-assisted semen analysis (CASA), detection of membrane functionality, acrosome integrity, mitochondrial integrity, CAT, SOD, GSH-PX, MDA, and ROS were conducted. The results showed that adding $50 \mathrm{mg} / \mathrm{L}$ OPC or $4 \mathrm{mg} / \mathrm{L}$ BLF could improve the quality of frozen sperm. Compared with $50 \mathrm{mg} / \mathrm{L}$ OPC alone, the combination of 50mg/L OPC and $2 \mathrm{mg} / \mathrm{L}$ BLF significantly increased the kinematic parameters of sperm, and sperm CAT, GSH-PX and SOD levels $(p<0.05)$, whereas the MDA of sperm was decreased $(p<0.05)$. These results indicated that compared to the addition of $50 \mathrm{mg} / \mathrm{L}$ OPC alone, a combination of $50 \mathrm{mg} / \mathrm{L}$ OPC and $2 \mathrm{mg} / \mathrm{L}$ BLF could further improve the quality of frozen semen. The results could provide theoretical data support for the development of a new protective agent and are significant for the cryopreservation of bovine semen in the future.
\end{abstract}

Keywords: oligomeric proanthocyanidins; antioxidant enzymes; Simmental bull; semen freezing; sperm analysis

\section{Introduction}

The cryopreservation of mammal semen is accompanied by the generation of oxidative stress, which could decrease sperm motility and induce DNA damage. Oxidative stress is one of the main reasons for the decrease in the success rate of artificial insemination [1]. In addition, mammalian sperms have relatively high polyunsaturated fatty acids in their plasma membranes (PUFA), which is why mammalian sperm are more susceptible to oxidative stress [2]. Oxidative stress is mainly caused by the imbalance of reactive oxygen species (ROS) and various antioxidant enzymes in semen, such as superoxide dismutase (SOD), glutathione peroxidase (GSH-PX), and catalase (CAT). Spermatozoa are protected by various antioxidants and antioxidant enzymes in the seminal plasma or in spermatozoa itself to prevent oxidative damage [3]. However, the antioxidant capacity of mature spermatozoa is low and not sufficient to cope with ROS produced during oxidative stress. In order to alleviate the oxidative stress caused by this imbalance, adding antioxidants to the diluent has become a necessary means [4]. Adding antioxidants has been found to improve semen quality in many species [5-9]. 
As a kind of natural polyphenol, oligomeric proanthocyanidins (OPC) exist widely in nature [10]. OPC have been found in some studies to protect cells from $\mathrm{H}_{2} \mathrm{O}_{2}$-induced oxidative stress [11], and also has many biological activities such as inhibiting apoptosis [12], anticancer [13], anti-aging [14], and antioxidants [15]. In terms of antioxidants, OPC could reduce blood pressure by relieving the oxidative stress level of mice [16]. OPC could also improve the antioxidant capacity of pig semen to improve the pregnancy rate of sows and the survival rate of piglets [17], because different antioxidants have a synergistic effect on the removal of ROS. As a natural plant extract, bamboo leaf flavonoids (BLF) have a strong antioxidant ability [18], in addition to having a strong antioxidant capacity. In addition, BLF have a very strong performance in immune regulation [19], as well as anti-inflammatory [20], anti-depression [21], and lipid-lowering properties [22]. In recent studies, it was found that the addition of BLF can reduce oxidative stress of cells by regulating ROS production and activities of various antioxidant enzymes [23]. A large number of studies have shown that OPC and BLF have a strong antioxidant ability, but they have not been used in cryopreservation of bovine semen.

Therefore, the purpose of this study was to research the effects of OPC and BLF on kinematic parameters, plasma membranes, acrosome integrity, antioxidant enzyme content, ROS and MDA levels of bovine semen freezing, observe whether the combination of OPC and BLF could further improve the quality of semen, and explore whether adding OPC and BLF could improve the quality of freeze-thawed bull semen.

\section{Results}

2.1. Effects of Different Concentrations OPC and BLF Separately on Parameters of Bovine Semen after Thawing

2.1.1. Effects of Different Concentrations of OPC addition on Kinematic Parameters of Frozen Bovine Semen

As shown in Table 1, adding 0, 10, 30, 50, and $70 \mathrm{mg} / \mathrm{L}$ OPC could improve the kinematic parameters of frozen semen. The effect of $50 \mathrm{mg} / \mathrm{L}$ OPC on the VCL, VAP, VSL kinematic parameters is higher than other concentrations $(p<0.05)$.

Table 1. Kinematic parameters for computer-aided sperm motility analysis after adding OPC.

\begin{tabular}{ccccccc}
\hline OPC $(\mathbf{m g} / \mathrm{L})$ & LIN (\%) & BCF $(\mathbf{H z})$ & VCL $(\mu \mathrm{m} / \mathbf{s})$ & VAP $(\mu \mathrm{m} / \mathbf{s})$ & VSL $(\mu \mathrm{m} / \mathbf{s})$ & ALH $(\mu \mathrm{m} / \mathbf{s})$ \\
\hline 0 & $63.78 \pm 1.55$ & $19.45 \pm 1.67$ & $123.18 \pm 1.08^{\mathrm{a}}$ & $96.31 \pm 3.91^{\mathrm{a}}$ & $78.56 \pm 3.28^{\mathrm{a}}$ & $1.62 \pm 0.08$ \\
10 & $63.66 \pm 1.48$ & $20.75 \pm 2.66$ & $124.80 \pm 2.12^{\mathrm{ab}}$ & $99.33 \pm 1.87^{\mathrm{ab}}$ & $79.45 \pm 1.11^{\mathrm{ac}}$ & $1.72 \pm 0.07$ \\
30 & $67.06 \pm 2.71$ & $19.59 \pm 2.49$ & $125.19 \pm 2.85^{\mathrm{ab}}$ & $99.83 \pm 1.66^{\mathrm{ab}}$ & $83.96 \pm 2.92^{\mathrm{ab}}$ & $1.75 \pm 0.12$ \\
50 & $65.56 \pm 1.99$ & $20.06 \pm 1.53$ & $130.61 \pm 2.45^{\mathrm{b}}$ & $104.67 \pm 3.52^{\mathrm{b}}$ & $85.63 \pm 3.84^{\mathrm{b}}$ & $1.64 \pm 0.09$ \\
70 & $66.63 \pm 2.21$ & $19.51 \pm 2.01$ & $126.95 \pm 2.53^{\mathrm{ab}}$ & $98.86 \pm 2.36^{\mathrm{ab}}$ & $84.59 \pm 2.81^{\mathrm{bc}}$ & $1.60 \pm 0.08$ \\
\hline
\end{tabular}

Abbreviations: Mean \pm SEM of average path velocity (VAP), straight line velocity (VSL), curvilinear velocity (VCL), amplitude of lateral head displacement (ALH), beat/cross frequency (BCF), and linearity (LIN). Different lowercase letters in the same column of data indicate significant differences $(p<0.05)$, and the same lowercase letters indicate insignificant differences $(p>0.05)$.

\subsubsection{Effects of Different Concentrations of BLF addition on Kinematic Parameters of} Frozen Bovine Semen

As shown in Table 2, adding 0, 2, 4, 6, and $8 \mathrm{mg} / \mathrm{L}$ BLF could improve the kinematic parameters of frozen semen. The effect of $4 \mathrm{mg} / \mathrm{L}$ BLF on the VCL, VAP, and VSL kinematic parameters is higher than other concentrations $(p<0.05)$.

2.1.3. Effects of Different Concentrations of OPC on the Antioxidant Enzyme Activity of Bovine Semen after Thawing

Results of SOD, CAT, and GSH-PX after the semen cryopreservation in 0, 10, 30, 50, and $70 \mathrm{mg} / \mathrm{L}$ of OPC are depicted in Figure 3. The SOD, CAT, and GSH-PX in the OPC $50 \mathrm{mg} / \mathrm{L}$ groups were greater $(p<0.01)$ than that in the different concentrations. 
Table 2. Kinematic parameters for computer-aided sperm motility analysis after adding BLF.

\begin{tabular}{ccccccc}
\hline BLF (mg/L) & LIN (\%) & BCF $(\mathbf{H z})$ & VCL $(\mu \mathrm{m} / \mathbf{s})$ & VAP $(\mu \mathrm{m} / \mathbf{s})$ & VSL $(\boldsymbol{\mu m} / \mathbf{s})$ & ALH $(\mu \mathrm{m} / \mathbf{s})$ \\
\hline 0 & $62.14 \pm 1.39$ & $21.09 \pm 1.32$ & $121.97 \pm 1.98^{\mathrm{a}}$ & $95.56 \pm 1.43^{\mathrm{a}}$ & $75.79 \pm 2.62^{\mathrm{a}}$ & $1.62 \pm 0.04$ \\
2 & $64.52 \pm 1.10$ & $20.03 \pm 1.81$ & $123.73 \pm 2.95^{\mathrm{a}}$ & $98.91 \pm 2.12^{\mathrm{ab}}$ & $79.84 \pm 2.96^{\mathrm{ab}}$ & $1.68 \pm 0.07$ \\
4 & $63.90 \pm 2.15$ & $19.17 \pm 1.17$ & $129.24 \pm 3.54^{\mathrm{b}}$ & $103.38 \pm 2.22^{\mathrm{b}}$ & $82.59 \pm 2.32^{\mathrm{b}}$ & $1.71 \pm 0.08$ \\
6 & $65.49 \pm 1.52$ & $19.86 \pm 1.61$ & $124.68 \pm 2.77^{\mathrm{ab}}$ & $102.43 \pm 2.82^{\mathrm{b}}$ & $81.65 \pm 1.23^{\mathrm{b}}$ & $1.68 \pm 0.07$ \\
8 & $65.85 \pm 2.26$ & $20.15 \pm 1.86$ & $122.16 \pm 1.79^{\mathrm{a}}$ & $100.37 \pm 2.66^{\mathrm{ab}}$ & $80.45 \pm 2.18^{\mathrm{ab}}$ & $1.67 \pm 0.08$ \\
\hline
\end{tabular}

Abbreviations: Mean \pm SEM of average path velocity (VAP), straight line velocity (VSL), curvilinear velocity (VCL), amplitude of lateral head displacement (ALH), beat/cross frequency (BCF), and linearity (LIN). Different lowercase letters in the same column of data indicate significant differences $(p<0.05)$, and the same lowercase letters indicate insignificant differences $(p>0.05)$.

2.1.4. Effects of Different Concentrations of OPC on the Integrity of the Plasma Membrane, Acrosome, and Total Motility after Thawing of Bovine Semen

Results of the plasma membrane, acrosome, and total motility after the semen cryopreservation in $0,10,30,50$, and $70 \mathrm{mg} / \mathrm{L}$ of OPC are depicted in Figure 1 . The total motility in the OPC $50 \mathrm{mg} / \mathrm{L}$ groups is greater $(p<0.01)$ than that in the different concentrations. The integrity of the plasma membrane and acrosome in the OPC $50 \mathrm{mg} / \mathrm{L}$ groups was greater $(p<0.05)$ than that in the different concentrations.
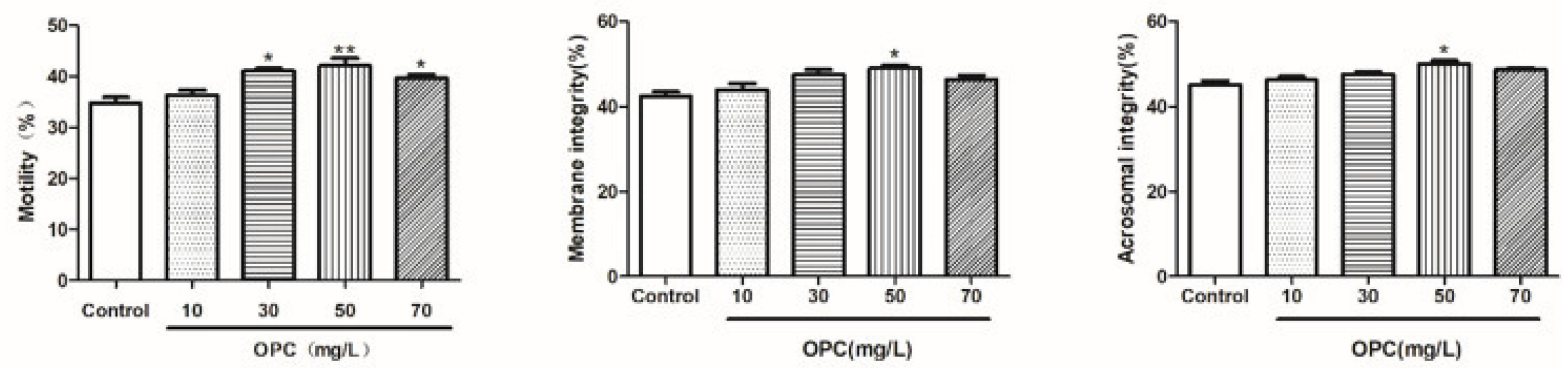

Figure 1. Effects of different concentrations of OPC on the integrity of the plasma membrane, acrosome, and total motility after thawing of bovine semen, * indicates a significant difference compared to that of the control group $\left({ }^{*} p<0.05 .{ }^{* *} p<0.01\right)$.

2.1.5. Effects of Different Concentrations of BLF on the Integrity of the Plasma Membrane, Acrosome, and Total Motility after Thawing of Bovine Semen

Results of the plasma membrane, acrosome, and total motility after the semen cryopreservation in $0,2,4,6$, and $8 \mathrm{mg} / \mathrm{L}$ of BLF are depicted in Figure 2. The total motility in the BLF $4 \mathrm{mg} / \mathrm{L}$ groups is greater $(p<0.01)$ than that in the different concentrations. The integrity of the plasma membrane and acrosome in the BLF $4 \mathrm{mg} / \mathrm{L}$ groups was greater $(p<0.05)$ than that in the different concentrations.
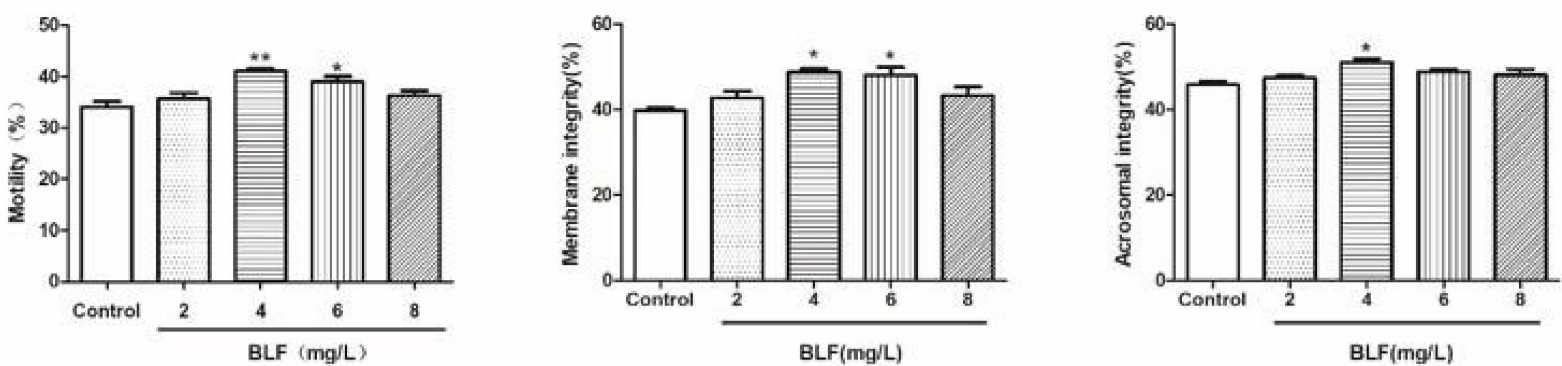

Figure 2. Effects of different concentrations of BLF on the integrity of the plasma membrane, acrosome, and total motility after thawing of bovine semen, ${ }^{*}$ indicates a significant difference compared to that of the control group $\left({ }^{*} p<0.05 .{ }^{* *} p<0.01\right)$. 

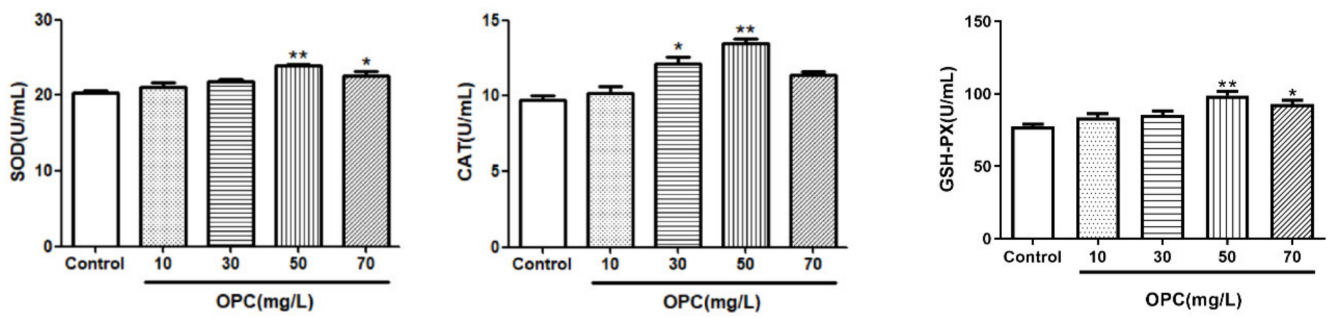

Figure 3. Effects of different concentrations of OPC on the antioxidant enzyme activity of bull semen after thawing, ${ }^{*}$ indicates a significant difference compared to that of the control group $(* p<0.05$. ** $p<0.01)$.

2.1.6. Effects of Different Concentrations of BLF on the Antioxidant Enzyme Activity of Bovine Semen after Thawing

Results of SOD, CAT, and GSH-PX after the semen cryopreservation in 0, 2, 4, 6, and $8 \mathrm{mg} / \mathrm{L}$ of BLF are depicted in Figure 4. The SOD, CAT and GSH-PX in the BLF $4 \mathrm{mg} / \mathrm{L}$ groups were greater $(p<0.05)$ than that in the different concentrations.
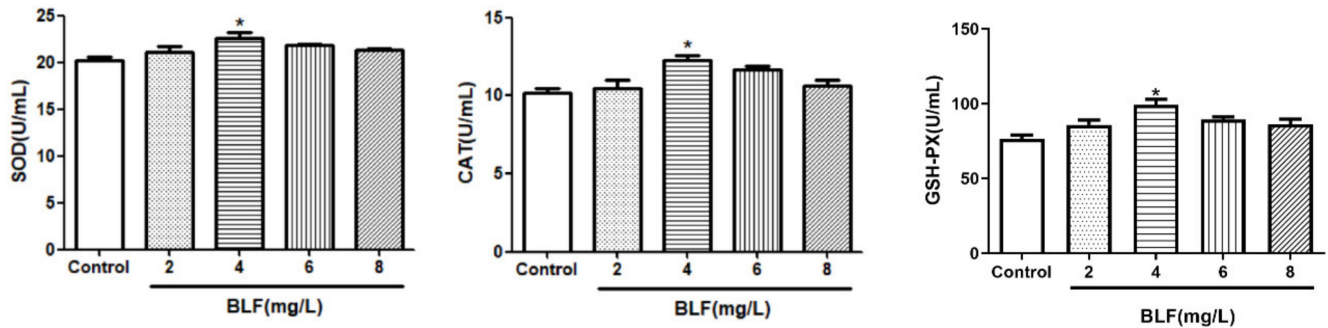

Figure 4. Effects of different concentrations of BLF on the antioxidant enzyme activity of bull semen after thawing, ${ }^{*}$ indicates a significant difference compared to that of the control group $\left({ }^{*} p<0.05\right.$. ** $p<0.01)$.

\subsubsection{Effects of Different Concentrations of OPC on the Oxidation Products of Bovine} Semen after Thawing

Results of MDA and ROS after the sperm cryopreservation in $0,10,30,50$, and $70 \mathrm{mg} / \mathrm{L}$ of OPC are depicted in Figure 5. The MDA in the OPC $50 \mathrm{mg} / \mathrm{L}$ groups were lower $(p<0.01)$ than that in the different concentrations. The ROS in the OPC $50 \mathrm{mg} / \mathrm{L}$ groups were lower $(p<0.05)$ than that in the different concentrations.
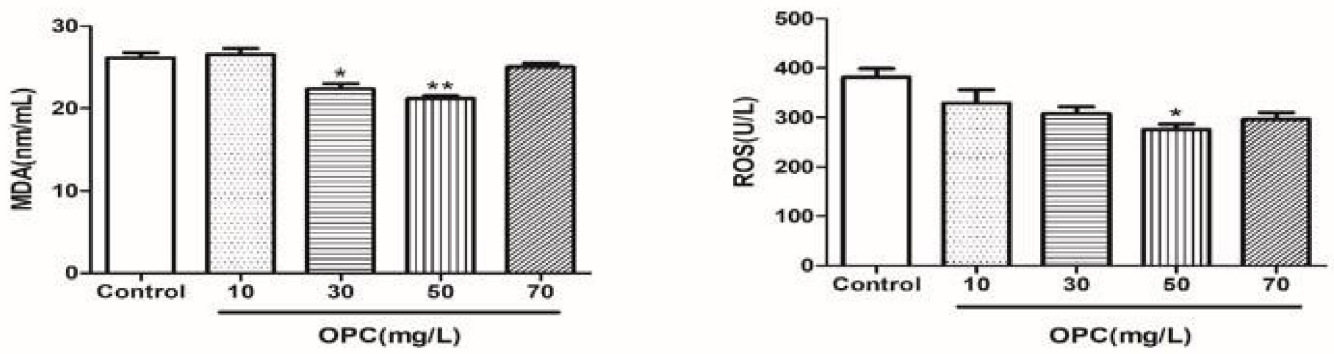

Figure 5. Effects of different concentrations of OPC on the oxidation products of cattle semen after thawing, * indicates a significant difference compared to that of the control group $(* p<0.05$. ** $p<0.01)$.

\subsubsection{Effects of Different Concentrations of BLF on the Oxidation Products of Bovine} Semen after Thawing

The results of MDA and ROS after the sperm cryopreservation in $0,2,4,6$, and $8 \mathrm{mg} / \mathrm{L}$ of BLF are depicted in Figure 6. The MDA in the BLF $4 \mathrm{mg} / \mathrm{L}$ groups were lower $(p<0.01)$ 
than that in the different concentrations. The ROS in the BLF $4 \mathrm{mg} / \mathrm{L}$ groups were lower $(p<0.05)$ than that in the different concentrations.
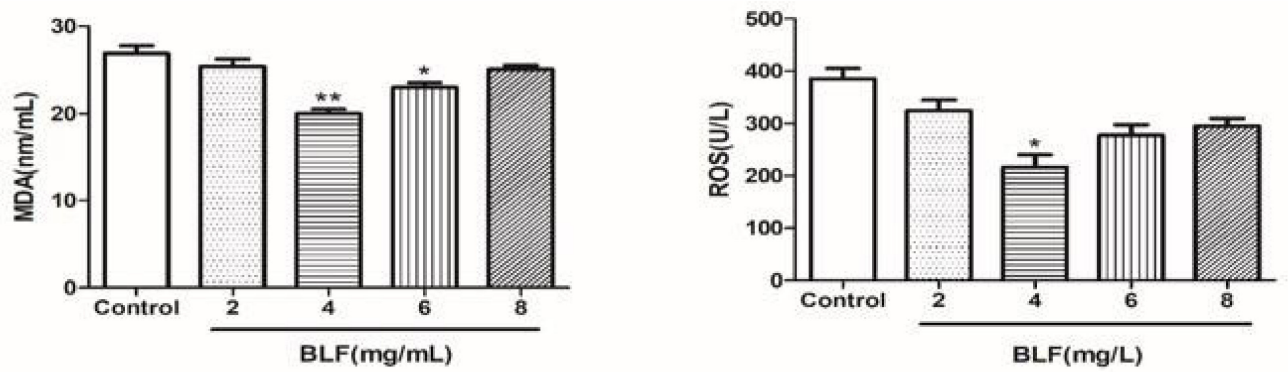

Figure 6. Effects of different concentrations of BLF on the oxidation products of cattle semen after thawing, ${ }^{*}$ indicates a significant difference compared to that of the control group $\left({ }^{*} p<0.05 .{ }^{* *} p<0.01\right)$.

2.2. Effects of Combined Addition of OPC and BLF on Parameters of Semen after Thawing 2.2.1. Effects of Combination of $50 \mathrm{mg} / \mathrm{L}$ OPC and Different Concentration of BLF on Kinematic Parameters of Frozen Bovine Semen

As shown in Table 3, the combination addition further improved the kinematic parameters of frozen semen compared to that with $50 \mathrm{mg} / \mathrm{L} \mathrm{OPC}$ alone. A combination of $50 \mathrm{mg} / \mathrm{L}$ OPC and $2 \mathrm{mg} / \mathrm{L}$ BLF significantly improved BCF, VAP, VCL, VSL, and ALH kinematic parameters $(p<0.05)$.

Table 3. Kinematic parameters of computer-aided sperm motility analysis after adding OPC and BLF.

\begin{tabular}{|c|c|c|c|c|c|c|}
\hline OPC (mg/L)/BLF (mg/L) & LIN (\%) & BCF (Hz) & VCL $(\mu \mathrm{m} / \mathrm{s})$ & VAP $(\mu \mathrm{m} / \mathrm{s})$ & VSL $(\mu \mathrm{m} / \mathrm{s})$ & ALH $(\mu \mathrm{m} / \mathrm{s})$ \\
\hline OPC50 & $65.71 \pm 1.99$ & $20.13 \pm 1.53^{a}$ & $130.32 \pm 2.45^{\mathrm{a}}$ & $104.41 \pm 3.52^{\mathrm{a}}$ & $85.35 \pm 3.84^{a}$ & $1.63 \pm 0.09^{a}$ \\
\hline OPC50 + BLF2 & $65.89 \pm 1.18$ & $24.60 \pm 1.02^{b}$ & $138.35 \pm 2.79^{b}$ & $110.65 \pm 1.84^{b}$ & $91.16 \pm 2.31^{b}$ & $1.71 \pm 0.08^{b}$ \\
\hline OPC50 + BLF4 & $64.51 \pm 2.75$ & $23.91 \pm 1.17^{\mathrm{ab}}$ & $137.45 \pm 1.65^{b}$ & $107.77 \pm 3.09^{a b}$ & $88.67 \pm 2.96^{a b}$ & $1.70 \pm 0.02^{b}$ \\
\hline OPC50 + BLF6 & $66.52 \pm 1.23$ & $22.61 \pm 1.79 \mathrm{ab}$ & $133.02 \pm 1.02^{a b}$ & $106.11 \pm 3.45^{\mathrm{ab}}$ & $88.49 \pm 1.68^{a b}$ & $1.68 \pm 0.07 \mathrm{ab}$ \\
\hline OPC50 + BLF8 & $64.84 \pm 2.84$ & $21.73 \pm 1.06^{a b}$ & $133.01 \pm 1.09 \mathrm{ab}$ & $105.74 \pm 3.61^{\mathrm{ab}}$ & $86.25 \pm 3.15^{a b}$ & $1.67 \pm 0.06^{\mathrm{ab}}$ \\
\hline
\end{tabular}

Abbreviations: Mean \pm SEM of average path velocity (VAP), straight line velocity (VSL), curvilinear velocity (VCL), amplitude of lateral head displacement (ALH), beat/cross frequency (BCF), and linearity (LIN). Different lowercase letters in the same column of data indicate significant differences $(p<0.05)$, and the same lowercase letters indicate insignificant differences $(p>0.05)$.

2.2.2. Effects of Combination of $50 \mathrm{mg} / \mathrm{L}$ OPC and Different Concentration of BLF on the Plasma Membrane, Acrosome, and Total Motility of Bovine Semen

As shown in Figure 7, the combination addition further improved the total motility, sperm plasma membrane integrity, and acrosome integrity of frozen semen compared to that with $50 \mathrm{mg} / \mathrm{L} \mathrm{OPC}$ alone. A combination of $50 \mathrm{mg} / \mathrm{L} \mathrm{OPC}$ and $2 \mathrm{mg} / \mathrm{L}$ BLF significantly improved total motility, sperm plasma membrane integrity, and acrosome integrity of semen $(p<0.05)$.
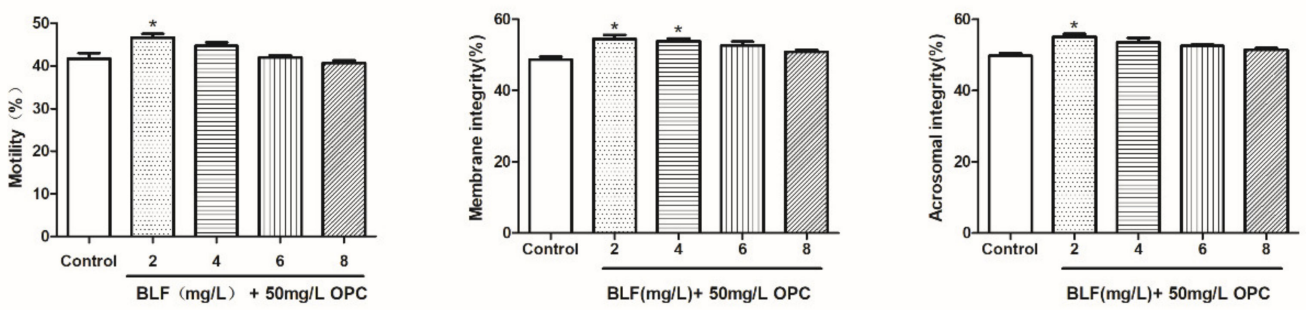

Figure 7. Effects of the combined use of OPC and BLF on the plasma membrane, acrosome, and total motility of bovine semen, ${ }^{*}$ indicates a significant difference compared to that of the control group (control group is $50 \mathrm{mg} / \mathrm{L} \mathrm{OPC})\left({ }^{*} p<0.05\right)$. 
2.2.3. Effects of Combination of $50 \mathrm{mg} / \mathrm{L} \mathrm{OPC}$ and Different Concentration of BLF on the on the Antioxidant Enzyme Activity of Bovine Semen after Thawing

As shown in Figure 8, the combination addition further improved the SOD, CAT, and GSH-PX of frozen semen compared to that with $50 \mathrm{mg} / \mathrm{L}$ OPC alone. A combination of $50 \mathrm{mg} / \mathrm{L} \mathrm{OPC}$ and $2 \mathrm{mg} / \mathrm{L} \mathrm{BLF}$ significantly improved SOD, CAT and GSH-PX in semen $(p<0.05)$.
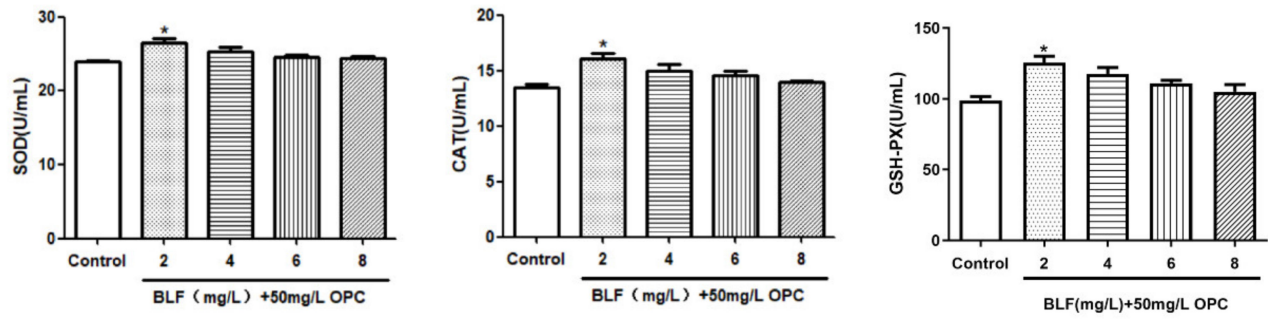

Figure 8. Effects of the combined use of OPC and BLF on the on the antioxidant enzyme activity of bull semen after thawing, ${ }^{*}$ indicates a significant difference compared to that of the control group (control group is $50 \mathrm{mg} / \mathrm{L} \mathrm{OPC})\left({ }^{*} p<0.05\right)$.

2.2.4. Effects of Combination of $50 \mathrm{mg} / \mathrm{L} \mathrm{OPC}$ and Different Concentration of BLF on the Oxidation Products of Bovine Semen after Thawing

As shown in Figure 9, the combination addition further reduced the ROS and MDA of frozen semen compared to that with $50 \mathrm{mg} / \mathrm{L}$ OPC alone. A combination of 50mg/L OPC and $2 \mathrm{mg} / \mathrm{L}$ BLF significantly reduced ROS and MDA in semen $(p<0.05)$.
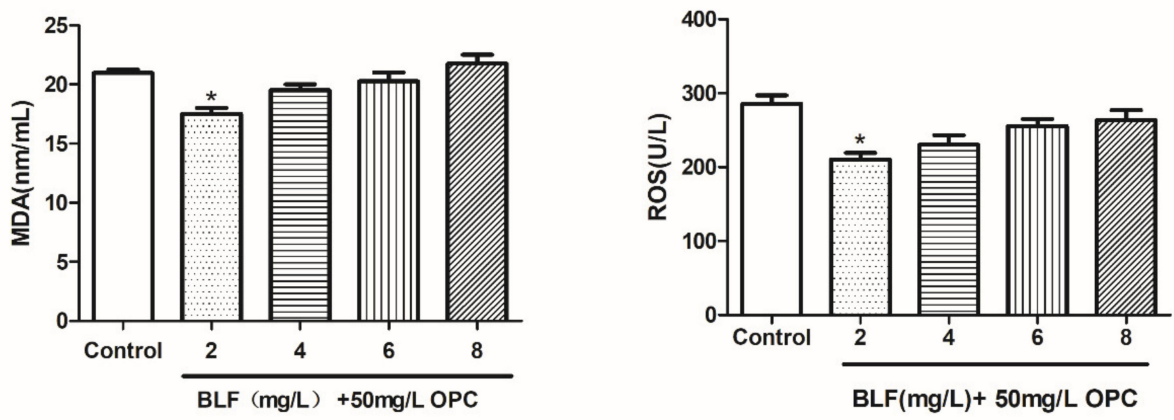

Figure 9. Effect of the combined use of OPC and BLF on the oxidation products of cattle semen after thawing, * indicates a significant difference compared to that of the control group (control group is $50 \mathrm{mg} / \mathrm{L} \mathrm{OPC})(* p<0.05)$.

\section{Materials and Methods}

\subsection{Chemicals}

In this study, OPC was acquired from Shenzhen Zhenqiang Biological Technology Co., LTD. BLF was acquired from Hubei Yongkuo Technology Co., LTD (WuHan, China).

\subsection{Experimental Design}

In this study, pooled semen was extended using a Tris extender with different levels of $\operatorname{OPC}(0,10,30,50$, and $70 \mathrm{mg} / \mathrm{L})$ and $\operatorname{BLF}(0,2,4,6$, and $8 \mathrm{mg} / \mathrm{L})$ or a combination of $\mathrm{OPC}$ and $\mathrm{BLF}(50 \mathrm{mg} / \mathrm{L} \mathrm{OPC}, 50 \mathrm{mg} / \mathrm{L} \mathrm{OPC}+2 \mathrm{mg} / \mathrm{L}, 50 \mathrm{mg} / \mathrm{L} \mathrm{OPC}+4 \mathrm{mg} / \mathrm{L}, 50 \mathrm{mg} / \mathrm{L}$ $\mathrm{OPC}+6 \mathrm{mg} / \mathrm{L}$, and $50 \mathrm{mg} / \mathrm{L} \mathrm{OPC}+8 \mathrm{mg} / \mathrm{L})$. Each experiment was repeated at least three times.

\subsection{Animals}

This study was conducted at Jilin Agricultural University in P.R. China and approved by the Experimental Animal Welfare and Ethics Committee of Jilin Agricultural University 
(number is 20200803002). Four bulls (4 years old) were used for semen collection. The uniformity of feed, housing, and light conditions were ensured. The bulls had free access to water and salt, and no additional antioxidants were present in the feed. The bull basal diet composition is shown in Table 4 , and the bull nutritional indicators in Table 5.

Table 4. Bull basal diet composition.

\begin{tabular}{cc}
\hline Ingredient & Dosage \\
\hline corn & $45 \%$ \\
soybean cake & $32 \%$ \\
wheat bran & $5 \%$ \\
rice bran meal & $5 \%$ \\
soybean germ meal & $6 \%$ \\
molasses & $2 \%$ \\
\hline bull special premix & $5 \%$ \\
\hline
\end{tabular}

Table 5. Bull nutritional indicators.

\begin{tabular}{cc}
\hline Ingredient & Dosage \\
\hline crude protein & $20 \%$ \\
moisture & $13 \%$ \\
crude ash & $7 \%$ \\
calcium & $0.6-0.7 \%$ \\
total phosphorus & $0.6-0.7 \%$ \\
sodium chloride & $0.8-1 \%$ \\
\hline
\end{tabular}

\subsection{Bull Semen Collection}

Semen samples were collected using an artificial vagina twice per week per bull; the samples were collected for 12 weeks. The criteria for cryopreservation were as follows. Semen samples were sent to the laboratory within $30 \mathrm{~min}$. The semen was held in a water bath at $37^{\circ} \mathrm{C}$ while the sperm concentration was estimated using a calibrated spectrophotometer and the motility of sperm was subjectively evaluated using microscopy at a concentration of at least $1 \times 10^{9}$ spermatozoa/mL, sperm motility $\geq 70 \%$, and abnormality $\leq 15 \%$. Healthy ejaculates were used in the experiments. After the initial assessment, the semen samples were mixed to eliminate individual differences.

\subsection{Basic Extender}

The basic extender was slightly modified from that described by Tarig et al. [24]. The basic ingredients are $1.1 \mathrm{~g}$ glucose, $1.48 \mathrm{~g}$ citric acid, $2.42 \mathrm{~g}$ tris, $0.06 \mathrm{~g}$ penicillin sodium, and $0.1 \mathrm{~g}$ streptomycin sulfate. All the chemicals were placed into a capacity bottle and double evaporative water was used to stabilize the capacity to $100 \mathrm{~mL}$, a magnetic stirrer was used to stir for $2 \mathrm{~h}$, then $20 \%$ egg yolk and 3\% glycerin were added, and stirred again for $2 \mathrm{~h}$ to completely dissolve. The basic diluent was divided evenly and OPC or BLF of different concentrations were added.

\subsection{Semen Processing}

After the quality evaluation, the samples were diluted and incubated in a water bath at $37{ }^{\circ} \mathrm{C}$ for $30 \mathrm{~min}$ for the full absorption of OPC and BLF by the sperm membrane. After that, the samples were packed in $0.25 \mathrm{~mL}$ straws (IMV, L'Aigle, France) with $8 \times 10^{6}$ sperm/straws, then cooled from $37^{\circ} \mathrm{C}$ to $4{ }^{\circ} \mathrm{C}$ for $2 \mathrm{~h}$ as previously described, and subsequently cooled for approximately $8 \mathrm{~min}$ from $4^{\circ} \mathrm{C}$ to $-140{ }^{\circ} \mathrm{C}$ by a turbo freezer (Minitubue, Germany). After that, the straws were transferred to a liquid nitrogen tank $\left(-196{ }^{\circ} \mathrm{C}\right)$ and stored for a long time before detection. 


\subsection{Evaluation of Post-Thawed Sperm}

\subsubsection{Computer Assisted Semen Analysis}

The kinematic parameters of sperm were analyzed using a sperm analyzer (developed jointly by Hamilton and IMV, IVOS II, 10871, 6 October 2017). Two straws were thawed by immersion in a water bath at $37^{\circ} \mathrm{C}$ for $30 \mathrm{~s}$. Each sample was analyzed at least three times. Five microliters were detected for each straw, and four fields were randomly examined. Average path velocity (VPA), straight line velocity (VSL), curvilinear velocity (VCL), amplitude of lateral head displacement (ALH), beat/cross frequency (BCF), and linearity (LIN) were recorded.

\subsubsection{Acrosome Integrity}

The sperm acrosome integrity was slightly modified from that described by Masoudi et al. [25]. The sample was centrifuged, and the resultant sperm pellet was obtained. It was then equilibrated in $96 \%$ ethanol for 10 minutes. Afterwards, the sperm was placed on a glass slide and fluorescein-isothiocyanate-conjugated pea lectin (PSA-FITC) (Sigma-Aldrich, St. Louis, MO, USA) was added. Slides were incubated for $20 \mathrm{~min}$, and glycerol was added to fix the sperm on the slide. At least 5 fields of view through a fluorescence microscope were observed, with a minimum of 200 sperm in each field, and the percentage of sperm with green fluorescence on the sperm head to the total number was calculated

\subsubsection{Plasma Membrane Integrity}

The method of measuring sperm acrosome integrity was slightly modified according to the method in the article published by R.A. Harrison et al. [26]. Using the double-staining method of carboxy fluorescein diacetate (CFDA) (Andy Forno Biotechnology (Wuhan) Co., Ltd., Wuhan, China) and propidium iodide (PI) (Coolaber), $0.46 \mathrm{mg}$ CFDA was dissolved in $1 \mathrm{~mL}$ dimethyl sulfoxide and $0.5 \mathrm{mg}$ PI was dissolved in $1 \mathrm{~mL}$ normal saline. It was stored at $-20{ }^{\circ} \mathrm{C}$ and protected from light. Afterwards, $20 \mu \mathrm{L}$ CFDA and $10 \mu \mathrm{L}$ PI were dissolved in $1 \mathrm{~mL}$ of PBS with a pH of 7.4 and $0.01 \mathrm{~mol} / \mathrm{L}$. A $20 \mu \mathrm{L}$ semen sample was then taken and $80 \mu \mathrm{L}$ staining solution was added to it. The cells were incubated at $37^{\circ} \mathrm{C}$ for $10 \mathrm{~min}$ and washed with PBS. After washing, $10 \mu \mathrm{L}$ was taken and observed under a fluorescence microscope, with a minimum of 200 sperm in each field, and the percentage of sperm with green fluorescence on the sperm head to the total number was calculated.

\subsubsection{Endogenous Antioxidant Indices Detection in the Frozen-Thawed Semen}

The determination of various endogenous antioxidant enzymes (superoxide dismutase, glutathione peroxidase, and catalase) was carried using an enzyme-linked immunoassay kit (Shanghai Enzyme Biotechnology Co., Ltd., Shanghai, China), according to the manufacturer's instructions. The sample tested was mixed with the sample diluent. After incubation, the enzyme-labeling reagent and stop solution were added in sequence. The resulting mixture was then placed into the microplate reader for analysis.

\subsubsection{MDA and ROS Concentration Determination in Post-Thawed Semen}

A bull MDA and ROS ELISA assay kit was used to determine the concentrations of MDA and ROS (Shanghai Enzyme Biotechnology Co. Ltd, Shanghai, China). The bovine semen was centrifuged repeatedly to destroy the sperm structure. Next, $40 \mu \mathrm{L}$ of diluent was added to the sample, and placed on a shaker to mix the semen and dilution thoroughly. It was then incubated in a $37^{\circ} \mathrm{C}$ incubator for $30 \mathrm{~min}$, washed with washing solution five times, then $50 \mu \mathrm{L}$ of enzyme-labeled reagent was added, again incubated in a $37^{\circ} \mathrm{C}$ incubator for $30 \mathrm{~min}$, and washed 5 times after equilibration. Two kinds of diluent shake were then added and mixed thoroughly. The entire procedure was performed for $10 \mathrm{~min}$ at $37^{\circ} \mathrm{C}$ in the dark. After adding the stop solution, the absorbance was measured with a microplate reader at a wavelength of $450 \mathrm{~nm}$, and the contents of MDA and ROS were calculated according to the standard curve. 


\subsection{Statistical Analyses}

The data were analyzed using GraphPad Prism 5 software. Unless otherwise stated, significance was set at $p<0.05$. The result is expressed as mean \pm SEM. A one-way analysis of variance was performed to evaluate sperm motility, acrosome integrity, plasma membrane integrity, antioxidant enzyme content, ROS level, oxidation product, malondialdehyde content, and mitochondrial membrane potential.

\section{Discussion}

In order to improve the quality of cryopreservation semen and reduce the effect of oxidative stress, adding antioxidants to cryopreservation diluents has become an important method [27]. Our results showed that adding $50 \mathrm{mg} / \mathrm{L} \mathrm{OPC} \mathrm{or} 4 \mathrm{mg} / \mathrm{L} \mathrm{BLF}$ could improve the quality of frozen semen. Measurements of $50 \mathrm{mg} / \mathrm{L} \mathrm{OPC}$ and $2 \mathrm{mg} / \mathrm{L} \mathrm{BLF}$ or $4 \mathrm{mg} / \mathrm{L}$ BLF and $30 \mathrm{mg} / \mathrm{L} \mathrm{OPC}$ were added in combination, and the quality of semen was further improved when compared to adding them separately.

Sperm motility is the main factor affecting reproductive efficiency. Furthermore, the kinematic parameters of sperm may be reliable indicators to evaluate the success of cryopreservation and fertilization [28]. In this study, it was found that adding OPC alone could significantly improve sperm motility and kinematic parameters after freezing. This suggests that OPC may act as an antioxidant to relieve sperm malformation rates and may improve pregnancy rates by improving sperm motility. The integrity of the plasma membrane and acrosome is an important factor in whether sperm could be inseminated or not, and antioxidants in the diluent have the ability to protect sperm, help protect sperm motility, plasma membrane, acrosome integrity, and fertilization ability [29,30]. In our research, it was found that after adding OPC, the sperm plasma membrane and acrosome intact rate were significantly improved, which may help sperm to pass through the zona pellucida and vitelline membrane and increase the pregnancy rate. MDA overproduction is one of the main causes of spermatozoa LPO. Studies have found that adding OPC can alleviate atherosclerosis in rats by increasing the content of SOD and GSH-PX and decreasing the level of MDA [31]. Similar results were also obtained in this study. After adding OPC, SOD, and GSH-PX contents in cryopreservation, semen was significantly increased, whereas the MDA level was significantly decreased. Excessive ROS is one of the main factors leading to oxidative stress of sperm, the imbalance between ROS, and various antioxidant enzymes in semen will result in decreased sperm motility, damaged morphology, and increased malformation rate [32-34]. In recent studies, it has been found that adding OPC could reduce the ROS level in boar semen and improve the total antioxidant capacity (T-AOC) [17]. This is consistent with our results. When OPC was added, the ROS level in semen was significantly reduced, and the antioxidant enzyme content, such as CAT, was significantly increased. This suggests that OPC may improve the sperm morphological parameters by increasing the level of various antioxidant enzymes in semen and decreasing the contents of MDA and ROS. The imbalance between the antioxidant enzyme content and ROS in semen is one of the main factors leading to oxidative stress, so adding antioxidants to diluent is necessary. Studies have found that add BLF could increase the production of antioxidant enzymes and mitochondrial membrane potential, and reduce oxidative stress and ROS production [23]. In our study, through the addition of BLF, the levels of various antioxidant enzymes, CAT, SOD and GSH-PX, were significantly improved, and there was also a significant reduction in ROS levels. Cryopreservation of semen could cause severe freezing damage. Freezing damage is often accompanied by inflammation, which often leads to the appearance of abnormal sperm. Recent studies have shown that BLF could reduce the release of inflammatory factors to improve inflammatory injury [21]. We observed through the sperm analyzer that the addition of BLF could significantly improve the abnormal motility of sperm. The levels of VSL, LIN, and VAP in sperm were also significantly improved, which may be due to BLF mitigating the release of inflammatory factors. Since the current cryopreservation process of semen is mostly carried out in an open environment, this could cause semen to be exposed to the air, causing bacterial con- 
tamination, and resulting in poor semen quality. It has been found that BLF could improve the immune function of chickens by improving the microflora [19]. This is consistent with our findings. Our research also found that BLF could improve the vitality of semen after thawing and other indicators. This may be due to the various biological activities of BLF.

Some studies have shown that different antioxidants have a synergistic effect on the removal of active oxygen. This is because they have different binding speeds with active free radicals and different ways of action [35]. On combining OPC and BLF, it was observed that the combination of two antioxidants could improve the quality of semen without other side effects. In addition, adding these substances could improve the vitality after freezing; however, this does not imply that they can improve the fertilization ability because there is no measurement of conception rate and other indicators, which is a limitation of this project.

In conclusion, adding $50 \mathrm{mg} / \mathrm{L}$ OPC or $4 \mathrm{mg} / \mathrm{L} \mathrm{BLF}$ could significantly improve the kinematic parameters of sperm, acrosome integrity, and plasma membrane integrity of bovine semen. However, a combination of $50 \mathrm{mg} / \mathrm{L}$ OPC and $2 \mathrm{mg} / \mathrm{L}$ BLF could further improve the kinematic parameters of sperm, and the integrity of the acrosome, plasma membrane. These results may be due to the addition of OPC, and BLF alleviating the levels of ROS and MDA, as well as an increasing the enzymatic activity of CAT, SOD, and GSH-PX.

Author Contributions: Conceptualization, W.L., J.Z. and J.W.; Methodology, H.W., Z.L. and J.Z.; Software, H.L.; Validation, P.L., C.Y., and Z.L.; Formal Analysis, H.W.; Investigation, J.Z.; Data Curation, H.W.; Writing-Original Draft Preparation, H.W.; Writing—Review and Editing, W.L. and J.W.; Supervision, W.L. and J.W.; Project administration, W.L.; Funding Acquisition, W.L. All authors have read and agreed to the published version of the manuscript.

Funding: This research was funded by the National Key Research and Development Program of China. grant number [2018YFE0122000] And The APC was funded by Jilin province science and technology development plan item. grant number [20200301031RQ].

Institutional Review Board Statement: This study was conducted at Jilin Agricultural University in China and approved by the Experimental Animal Welfare and Ethics Committee of Jilin Agricultural University (number is 20200803002).

Informed Consent Statement: Not applicable.

Data Availability Statement: Not applicable.

Conflicts of Interest: The authors declare no conflict of interest.

Sample Availability: Samples of the compounds are not available from the authors.

\section{References}

1. Bell, M.; Wang, R.; Hellstrom, W.J.; Sikka, S.C. Effect of cryoprotective additives and cryopreservation protocol on sperm membrane lipid peroxidation and recovery of motile human sperm. J. Androl. 1993, 14, 472-478. [PubMed]

2. Gandini, L.; Lombardo, F.; Paoli, D.; Caponecchia, L.; Familiari, G.; Verlengia, C.; Dondero, F.; Lenzi, A. Study of apoptotic DNA fragmentation in human spermatozoa. Hum. Reprod. 2000, 15, 830-839. [CrossRef] [PubMed]

3. O'Flaherty, C. The enzymatic antioxidant system of human spermatozoa. Adv. Androl. 2014, 2014, 626374. [CrossRef]

4. Kim, S.-H.; Yu, D.-H.; Kim, Y.-J. Effects of cryopreservation on phosphatidylserine translocation, intracellular hydrogen peroxide, and DNA integrity in canine sperm. Theriogenology 2010, 73, 282-292. [CrossRef]

5. Hu, J.-H.; Li, Q.-W.; Zhang, T.; Jiang, Z.-L. Effect of Gynostemma Pentaphyllum polysaccharide on boar spermatozoa quality following freezing-thawing. Cryobiology 2009, 59, 244-249. [CrossRef]

6. Premrov Bajuk, B.; Pihlar, T.; Pogačnik, N.; Klinc, P. Dialysis of the goat semen and its effect on the quality of frozen/thawed spermatozoa processed in the presence of egg yolk. Anim. Reprod. Sci. 2018, 198, 65-73. [CrossRef]

7. Neagu, V.R.; García, B.M.; Sandoval, C.S.; Rodríguez, A.M.; Ferrusola, C.O.; Fernández, L.G.; Tapia, J.A.; Peña, F.J. Freezing dog semen in presence of the antioxidant butylated hydroxytoluene improves postthaw sperm membrane integrity. Theriogenology 2010, 73, 645-650. [CrossRef]

8. Lv, C.; Larbi, A.; Wu, G.; Hong, Q.; Quan, G. Improving the quality of cryopreserved goat semen with a commercial bull extender supplemented with resveratrol. Anim. Reprod. Sci. 2019, 208, 106127. [CrossRef] 
9. Appiah, M.O.; He, B.; Lu, W.; Wang, J. Antioxidative effect of melatonin on cryopreserved chicken semen. Cryobiology 2019, 89 90-95. [CrossRef]

10. Ferreira, D.; Slade, D. Oligomeric proanthocyanidins: Naturally occurring O-heterocycles. Nat. Prod. Rep. 2002, 19, 517-541. [CrossRef]

11. Sun, C.; Jin, W.; Shi, H. Oligomeric proanthocyanidins protects A549 cells against H2O2-induced oxidative stress via the Nrf2-ARE pathway. Int. J. Mol. Med. 2017, 39, 1548-1554. [CrossRef] [PubMed]

12. Yin, M.-H.; Wang, Y.-T.; Li, Q.; Lv, G.-F. Oligomeric proanthocyanidins inhibit apoptosis of chondrocytes induced by interleukin-1 $\beta$ Mol. Med. Rep. 2017, 16, 4195-4200. [CrossRef]

13. Toden, S.; Ravindranathan, P.; Gu, J.; Cardenas, J.; Yuchang, M.; Goel, A. Oligomeric proanthocyanidins (OPCs) target cancer stem-like cells and suppress tumor organoid formation in colorectal cancer. Sci. Rep. 2018, 8, 3335. [CrossRef] [PubMed]

14. Yokozawa, T.; Park, C.H.; Noh, J.S.; Roh, S.S. Role of oligomeric proanthocyanidins derived from an extract of persimmon fruits in the oxidative stress-related aging process. Molecules 2014, 19, 6707-6726. [CrossRef]

15. Shi, X.; Shang, F.; Zhang, Y.; Wang, R.; Jia, Y.; Li, K. Persimmon oligomeric proanthocyanidins alleviate ultraviolet B-induced skin damage by regulating oxidative stress and inflammatory responses. Free Radic. Res. 2020, 54, 765-776. [CrossRef]

16. Zhu, F.-Q.; Hu, J.; Lv, F.-H.; Cheng, P.; Gao, S. Effects of oligomeric grape seed proanthocyanidins on L-NAME-induced hypertension in pregnant mice: Role of oxidative stress and endothelial dysfunction. Phytother. Res. 2018, 32, $1836-18477$. [CrossRef]

17. Li, Q.; Shaoyong, W.; Li, Y.; Chen, M.; Hu, Y.; Liu, B.; Yang, G.; Hu, J. Effects of oligomeric proanthocyanidins on quality of boar semen during liquid preservation at $17^{\circ} \mathrm{C}$. Anim. Reprod. Sci. 2018, 198, 47-56. [CrossRef]

18. Gong, J.; Xia, D.; Huang, J.; Ge, Q.; Mao, J.; Liu, S.; Zhang, Y. Functional components of bamboo shavings and bamboo leaf extracts and their antioxidant activities in vitro. J. Med. Food 2015, 18, 453-459. [CrossRef]

19. Shu, G.; Kong, F.; Xu, D.; Yin, L.; He, C.; Lin, J.; Fu, H.; Wang, K.; Tian, Y.; Zhao, X. Bamboo leaf flavone changed the community of cecum microbiota and improved the immune function in broilers. Sci. Rep. 2020, 10, 12324. [CrossRef] [PubMed]

20. Wedler, J.; Daubitz, T.; Schlotterbeck, G.; Butterweck, V. In vitro anti-inflammatory and wound-healing potential of a Phyllostachys edulis leaf extract-identification of isoorientin as an active compound. Planta Med. 2014, 80, 1678-1684. [CrossRef]

21. Gan, T.; Zhou, X.Y.; Fan, G.X.; Ling, H.W.; Ying, C.J.; Li, W. Effect and mechanism of bamboo leaf flavonoids on depression in type 2 diabetic rats. Zhonghua Yi Xue Za Zhi 2019, 99, 1251-1255. [PubMed]

22. Yang, C.; Yifan, L.; Dan, L.; Qian, Y.; Ming-yan, J. Bamboo leaf flavones and tea polyphenols show a lipid-lowering effect in a rat model of hyperlipidemia. Drug Res. 2015, 65, 668-671. [CrossRef] [PubMed]

23. Yu, Y.; Li, Z.; Cao, G.; Huang, S.; Yang, H. Bamboo leaf flavonoids extracts alleviate oxidative stress in HepG2 cells via naturally modulating reactive oxygen species production and Nrf2-mediated antioxidant defense responses. J. Food Sci. 2019, 84, 1609-1620. [CrossRef]

24. Tarig, A.A.; Wahid, H.; Rosnina, Y.; Yimer, N.; Goh, Y.M.; Baiee, F.H.; Khumran, A.M.; Salman, H.; Ebrahimi, M. Effect of different concentrations of egg yolk and virgin coconut oil in Tris-based extenders on chilled and frozen-thawed bull semen. Anim. Reprod. Sci. 2017, 182, 21-27. [CrossRef] [PubMed]

25. Patel, D.; Shukla, S.; Gupta, S. Apigenin and cancer chemoprevention: Progress, potential and promise (review). Int. J. Oncol. 2007, 30, 233-245. [CrossRef]

26. Pei, Y.; Yang, L.; Wu, L.; He, H.; Geng, G.; Xu, D.; Chen, H.; Li, Q. Combined effect of apigenin and ferulic acid on frozen-thawed boar sperm quality. Anim. Sci. J. 2018, 89, 956-965. [CrossRef]

27. Kumar, A.; Prasad, J.K.; Srivastava, N.; Ghosh, S.K. Strategies to minimize various stress-related freeze-thaw damages during conventional cryopreservation of mammalian spermatozoa. Biopreservation Biobanking 2019, 17, 603-612. [CrossRef] [PubMed]

28. Mortimer, S.T. CASA-Practical aspects. J. Androl. 2000, 21, 515-524. [PubMed]

29. Silva, P.F.N.; Gadella, B.M. Detection of damage in mammalian sperm cells. Theriogenology 2006, 65, 958-978. [CrossRef]

30. Bucak, M.N.; Tuncer, P.B.; Sarı̈zkan, S.; Başpınar, N.; Taşpınar, M.; Coyan, K.; Bilgili, A.; Akalın, P.P.; Büyükleblebici, S.; Aydos, S.; et al. Effects of antioxidants on post-thawed bovine sperm and oxidative stress parameters: Antioxidants protect DNA integrity against cryodamage. Cryobiology 2010, 61, 248-253. [CrossRef]

31. Zhou, Q.; Han, X.; Li, R.; Zhao, W.; Bai, B.; Yan, C.; Dong, X. Anti-atherosclerosis of oligomeric proanthocyanidins from Rhodiola rosea on rat model via hypolipemic, antioxidant, anti-inflammatory activities together with regulation of endothelial function. Phytomedicine 2018, 51, 171-180. [CrossRef] [PubMed]

32. Büyükleblebici, S.; Tuncer, P.B.; Bucak, M.N.; Eken, A.; Sarı̈zkan, S.; Taşdemir, U.; Endirlik, B.Ü. Cryopreservation of bull sperm: Effects of extender supplemented with different cryoprotectants and antioxidants on sperm motility, antioxidant capacity and fertility results. Anim. Reprod. Sci. 2014, 150, 77-83. [CrossRef]

33. Hussaini, S.M.H.; Zhandi, M.; Shahneh, A.Z.; Sharafi, M.; Nejati-Javaremi, A.; Yousefi, A.; Emamverdi, M.; Shehab-El-Deen M.A.M.M.; Pastor, F.M. Effect of tert-butyl hydroquinone on bull semen cryopreservation. Cryo Lett. 2018, 38, $372-378$.

34. Salmon, V.M.; Leclerc, P.; Bailey, J.L. Novel technical strategies to optimize cryopreservation of goat semen using cholesterolloaded cyclodextrin. Cryobiology 2017, 74, 19-24. [CrossRef] [PubMed]

35. Ren, F.; Feng, T.; Dai, G.; Wang, Y.; Zhu, H.; Hu, J. Lycopene and alpha-lipoic acid improve semen antioxidant enzymes activity and cashmere goat sperm function after cryopreservation. Cryobiology 2018, 84, 27-32. [CrossRef] [PubMed] 